\title{
Influence of process variables on release properties of paracetamol tablets
}

\author{
GBENGA ALEBIOWU ${ }^{1 *}$ \\ OLUDELE ADELANWA ITIOLA \\ ${ }^{1}$ Department of Pharmaceutics \\ Faculty of Pharmacy, Obafemi Awolowo \\ University, Ile-Ife, Nigeria \\ ${ }^{2}$ Department of Pharmaceutics and \\ Industrial Pharmacy, Faculty of \\ Pharmacy, University of Ibadan \\ Ibadan, Nigeria
}

\begin{abstract}
A $2^{3}$ factorial experimental design has been used to quantitatively study individual and interaction effects of the nature of binder $(\mathrm{N})$, binder concentration $(c)$ and relative density of tablet $(d)$ on the disintegration time (DT) and dissolution times, $t_{1}, t_{50}$ and $t_{90}$, of paracetamol tablet formulations. The factorial design was also used to study the quantitative effects of pregelatinization of starch binders on these parameters, i.e., N, $c$ and $d$. In general, the most common ranking of the individual effects on $D T$, $t_{1}, t_{50}$ and $t_{90}$ for native/native, pregelatinized/pregelatinized and native/pregelatinized starch binder formulations was $c>d>\mathrm{N}$. For interaction effects, the most common ranking was $\mathrm{N}-c>c-d>\mathrm{N}-d$ for all formulations. The results generally showed that $c$ can considerably affect $D T, t_{1}, t_{50}$ and $t_{90}$ of the tablets.
\end{abstract}

Keywords: pregelatinization, starch, sorghum, plantain, disintegration, dissolution

In the search for the best possible solution to a particular formulation problem, methodologies have been developed for structuring typical pharmaceutical development work into a framework, whereby sophisticated mathematical techniques could be employed to arrive at an optimal solution. One of the methods is factorial experimental design, which permits evaluation of factor effects and factor interactions and gives quantitative estimates of responses. This type of analysis has been employed by various workers (1-5) and has been shown to be relevant to formulation and assessment of pharmaceutical systems.

Starch has been recognized as one of the most commonly used excipients in tablet formulation (6) and has been modified by pregelatinization in order to produce cold water-swellable starches (7). Such modification would be expected to affect various properties of starches, including their swellability and disintegrant properties. Sorghum and plantain starches obtained from Sorghum bicolor L. (Poaceae) and Musa paradisiaca L. (Musaceae) respectively, have been investigated as binders and disintegrants in tablet formulations $(8,9)$. In our previous work, it was shown that the swelling and water retention capacities (parameters likely to have an effect on the disintegration ability of the two

\footnotetext{
*Correspondence, e-mail: galebiowu@yahoo.co.uk; galebiowu@rediffmail.com
} 
starches) of the pregelatinized form of the two starches are higher (10). It has also been revealed that pregelatinization of the starches affected their abilities as binders and disintegrants $(5,11,12)$

Disintegration of tablets has been reported to influence the dissolution process, since it assists in increasing the area of contact between the solid and liquid (3). Hence, this paper reports the results of a $2^{3}$ factorial experimental design carried out to study and compare the quantitative effects of the nature of starch binding agent $(\mathrm{N})$, concentration of starch binding agent $(c)$ and relative density of paracetamol tablets $(d)$ on disintegration time, $D T$, and dissolution parameters $t_{1}, t_{50}$ and $t_{90}$, $\left[t_{1}\right.$ is the time required for breakup of the tablets into fragments (13), while $t_{50}$ and $t_{90}$ are the times for $50 \%$ and $90 \%$ of the paracetamol to be released, respectively], to determine the effects that pregelatinization of the starches would have on their quantitative effects and, to evaluate the effect of different types of starches on the release property of paracetamol tablets. Corn starch $\mathrm{BP}$ and its pregelatinized form was used as reference standard.

\section{EXPERIMENTAL}

\section{Materials}

The materials used were paracetamol BP and corn starch BP (14) (BDH Chemicals Ltd, UK), lactose BP (AB Knight and Co, London, UK, sorghum (Sorghum bicolor L.) and plantain (Musa paradisiaca L.) starches prepared in our laboratory. The pregelatinized forms of the three starches were also prepared in our laboratory.

\section{Preparation of native and pregelatinized starches}

Sorghum and plantain starches were prepared according to the established procedure (15). Fully pregelatinized forms of the two starches and of the official corn starch BP were prepared as described earlier $(16,17)$. Aqueous slurry of each starch was made with $100 \mathrm{~g}$ of starch powder in $100 \mathrm{~mL}$ of deionized water and then heated at $55^{\circ} \mathrm{C}$ under stirring for $10 \mathrm{~min}$. The resultant paste was crisp-dried in a hot air oven (Gallenkamp, Model OV-335, Vindon Scientific Ltd, UK) at $60{ }^{\circ} \mathrm{C}$ for $48 \mathrm{~h}$. The dried mass was powdered in a laboratory mill (Christy and Norris Ltd, UK). All starches were passed through a number 120 mesh sieve $(125 \mathrm{~mm})$ before use.

\section{Preparation of granules}

Batches $(300 \mathrm{~g})$ of a basic formulation of paracetamol $(85 \% \mathrm{~m} / \mathrm{m})$, corn starch $(7 \%$ $\mathrm{m} / \mathrm{m}$ ) and lactose $(8 \% \mathrm{~m} / \mathrm{m})$ were dry-mixed for $5 \mathrm{~min}$ in a Hobart planetary mixer (model N-50, Hobart Manufacturing Co., UK) and then moistened with appropriate amounts of the starch mucilage used to produce samples containing different concentrations of the starch binders. Massing was continued for $5 \mathrm{~min}$ and the wet masses were granulated by passing them manually through a number 12 -mesh sieve $(1400 \mu \mathrm{m})$. The granules 
G. Alebiowu and O. Adelanwa Itiola: Influence of process variables on release properties of paracetamol tablets, Acta Pharm. 57 (2007) 73-86.

were dried in a hot air oven for $24 \mathrm{~h}$ at $60{ }^{\circ} \mathrm{C}$ and then resieved through a number 16mesh $(1000 \mu \mathrm{m})$. The loading efficiency of paracetamol in the granules was then determined by spectrophotometric assay of paracetamol at $249 \mathrm{~nm}$ and was found to be higher than $95 \%$. The moisture content of the formulation as determined with an Ohaus moisture balance Ohaus scale corporation, USA) was between 1.0 and $2.0 \%, \mathrm{~m} / \mathrm{m}$. Particle densities were determined by the pycnometer method with benzene as the displacement fluid.

\section{Preparation of tablets}

Quantities (550 mg) of 500-1000- $\mu \mathrm{m}$ size fractions of the granules formulations were compressed for $1 \mathrm{~min}$ into tablets with predetermined loads (95.95-159.92 MPa) using a Carver hydraulic hand press (Model C, Carver Inc., USA). Before each compression, the die (12.5 mm diameter) and the flat faced punches were lubricated with a $2 \%(\mathrm{~m} / \mathrm{m})$ dispersion of magnesium stearate in benzene. After ejection, the tablets were stored over silica gel for $24 \mathrm{~h}$ to allow for elastic recovery and hardening, and prevent falsely low yield values. Their masses, $m$, and dimensions were then determined to within $\pm 1 \mathrm{mg}$ and $0.01 \mathrm{~mm}$, respectively, and their relative densities, $d$, were calculated using the equation:

$$
d=m / V_{\mathrm{t}} \rho_{\mathrm{s}}
$$

where $V_{\mathrm{t}}$ is the volume $\left(\mathrm{cm}^{3}\right)$ of the tablet and $\rho_{\mathrm{s}}$ is the particle density $\left(\mathrm{g} \mathrm{cm}^{-3}\right)$ of the solid material.

\section{Disintegration test}

The disintegration time, DT, of the tablets was determined in distilled water at $37 \pm$ $0.5^{\circ} \mathrm{C}$ using a BP Manesty disintegration test unit (Manesty Machines Ltd., UK). Tablets were placed on the wire mesh just above the surface of the distilled water in the tube and the apparatus was started simultaneously with a stop clock. The time taken for each tablet to disintegrate and all the granules to go through the wire mesh was recorded. Determinations were made in triplicate.

\section{Dissolution test}

The dissolution rate of the tablets was determined at $37 \pm 0.5^{\circ} \mathrm{C}$ in 1 liter of $0.1 \mathrm{~mol}$ $\mathrm{L}^{-1} \mathrm{HCl}$ using an Erweka dissolution rate apparatus (Erweka, Germany) and a stirring speed of 100 revolutions per minute according to USP 24 (18). The tablet was placed in the rotating basket and $5 \mathrm{~mL}$ of the medium was sampled with a pipette and filtered. The same quantity of the medium was added at the same temperature immediately after each sampling to keep the volume of the dissolution medium constant. The concentration of dissolved paracetamol in the medium was determined spectrophotometrically at $249 \mathrm{~nm}$ with a Unicam $8620 \mathrm{UV} /$ visible spectrophotometer (Pye Unicam, UK). All determinations were made in triplicate or more and the results are given as average values. 
G. Alebiowu and O. Adelanwa Itiola: Influence of process variables on release properties of paracetamol tablets, Acta Pharm. 57 (2007) 73-86.

\section{Experimental design}

To study the effect of the nature of starch as a binding agent, its concentration and relative density of the tablet on disintegration and dissolution times of paracetamol tablets, experiments were performed in a factorial design that involved the application of simple statistics (1-5). In this factorial design, formulations were only mathematically combined. The basis of the experimental design was that each of the three variables was utilized at a »high « level (denoted by subscript $\mathrm{H}$ ) and a »low « level (denoted by subscript L). The number of experiments in the design was $2^{3}$, i.e., 8.

Using the above nomenclature, the various combinations between the variables used in the design were:

$$
\begin{aligned}
& \mathrm{N}_{\mathrm{L}} c_{\mathrm{L}} d_{\mathrm{L}}, \mathrm{N}_{\mathrm{L}} c_{\mathrm{H}} d_{\mathrm{L}}, \mathrm{N}_{\mathrm{L}} c_{\mathrm{H}} d_{\mathrm{H}}, \mathrm{N}_{\mathrm{L}} c_{\mathrm{L}} d_{\mathrm{H}}, \\
& \mathrm{N}_{\mathrm{H}} c_{\mathrm{H}} d_{\mathrm{L}}, \mathrm{N}_{\mathrm{H}} c_{\mathrm{H}} d_{\mathrm{H}}, \mathrm{N}_{\mathrm{H}} c_{\mathrm{L}} d_{\mathrm{H}}, \mathrm{N}_{\mathrm{H}} c_{\mathrm{L}} d_{\mathrm{L}}
\end{aligned}
$$

where $\mathrm{N}_{\mathrm{L}}$ nature of starch binding agent (native sorghum starch, native plantain starch, pregelatinized starch - if used in combination with a native starch formulation) and $\mathrm{N}_{\mathrm{H}}$ nature of starch binding agent (native plantain starch, native corn starch, native sorghum starch). Native plantain starch represents low level only when in combination with native corn starch, while native sorghum starch represents high level only when in combination with pregelatinized sorghum starch. The choice of $\mathrm{N}_{\mathrm{L}}$ or $\mathrm{N}_{\mathrm{H}}$ was based on results and our experience with the starches $(10,19) \cdot c_{\mathrm{L}}$ - concentration of the starch binding agent $(0.5 \%, m / m), c_{\mathrm{H}}-$ concentration of the starch binding agent $(4.0 \% \mathrm{~m} / \mathrm{m}), d_{\mathrm{L}}-$ tablet relative density of $0.80 ; d_{\mathrm{H}}$ - tablet relative density of 0.90 .

By grouping the results from the combinations into a number of sets, it was possible to assess the effects that each of the three variables separately had on the disintegration and dissolution times of the tablets and determine whether the variables were interacting or acting independently of each other.

The effects of increasing N, from its "low « level to its "high « level, on the disintegration time and dissolution parameters were found by summing up all the disintegration or dissolution time results of samples containing »high « levels of $\mathrm{N}$ and subtracting the sum of the results of samples containing "low « levels of $\mathrm{N}$. That is:

$$
\frac{1}{4}\left[\begin{array}{c}
\left(\mathrm{N}_{\mathrm{L}} c_{\mathrm{L}} d_{\mathrm{L}}+\mathrm{N}_{\mathrm{H}} c_{\mathrm{H}} d_{\mathrm{L}}+\mathrm{N}_{\mathrm{H}} c_{\mathrm{H}} d_{\mathrm{H}}+\mathrm{N}_{\mathrm{H}} c_{\mathrm{L}} d_{\mathrm{H}}\right)- \\
\left(\mathrm{N}_{\mathrm{L}} c_{\mathrm{L}} d_{\mathrm{L}}+\mathrm{N}_{\mathrm{L}} c_{\mathrm{H}} d_{\mathrm{L}}+\mathrm{N}_{\mathrm{L}} c_{\mathrm{H}} d_{\mathrm{H}}+\mathrm{N}_{\mathrm{L}} c_{\mathrm{L}} d_{\mathrm{H}}\right)
\end{array}\right]
$$

The effects of the concentration of binding agent, $c$, and relative density of binding agent, $d$, were calculated similarly.

To determine whether there was any interaction between any two variables, the results of the combinations in which they appeared together at either »high « or »low « levels were summed up and the sum of other combinations was subtracted to obtain the interaction coefficient. For example, for $\mathrm{N}$ and $c$, we have: 


$$
\frac{1}{4}\left[\begin{array}{c}
\left(\mathrm{N}_{\mathrm{L}} c_{\mathrm{L}} d_{\mathrm{L}}+\mathrm{N}_{\mathrm{L}} c_{\mathrm{L}} d_{\mathrm{H}}+\mathrm{N}_{\mathrm{H}} c_{\mathrm{H}} d_{\mathrm{H}}+\mathrm{N}_{\mathrm{H}} c_{\mathrm{H}} d_{\mathrm{L}}\right)- \\
\left(\mathrm{N}_{\mathrm{L}} c_{\mathrm{H}} d_{\mathrm{L}}+\mathrm{N}_{\mathrm{L}} c_{\mathrm{H}} d_{\mathrm{H}}+\mathrm{N}_{\mathrm{H}} c_{\mathrm{L}} d_{\mathrm{L}}+\mathrm{N}_{\mathrm{H}} c_{\mathrm{L}} d_{\mathrm{H}}\right)
\end{array}\right]
$$

A zero result indicates no interaction, but if the interaction coefficient was significantly removed from zero, then the two variables concerned were interacting with each other. The extent of removal from zero is a measure of the magnitude of interaction (15). All measurements were made in triplicate and the results given are the mean values. These results were subjected to the analysis of variance (ANOVA).

\section{RESULTS AND DISCUSSION}

Table 1 shows the values of disintegration and dissolution times of paracetamol tablets for the different combinations. The values were used to calculate the independent and interaction coefficient values (i.e., factor effects and factor interactions) using the relevant expressions as presented in Tables II and III. There were both positive and negative influences on the disintegration and dissolution properties of the tablets. Positive influence indicates that a particular parameter has increased while negative influence indicates that the value of the parameter has decreased. The choice of $\mathrm{N}_{\mathrm{L}}$ or $\mathrm{N}_{\mathrm{H}}$ was based on the results presented by previous workers and our experience with the starches $(10$, 19).

\section{Individual effects}

This involves the effect that the concentration of starch binder $(c)$, nature of starch binder $(\mathrm{N})$ and relative density of tablet $(d)$ would have on the disintegration and dissolution parameters of paracetamol tablets. Rankings of the individual effects of the variables are shown in Table IV.

In considering native/native starch combinations, no common ranking (Table IV) of the individual effects of the variables on DT was observed although $d$ seems to have a higher effect. On $t_{50}$ it was $d>c>\mathrm{N}$, on $t_{90}$ was $\mathrm{N}>c>d$ and on $t_{1} c>d>\mathrm{N}$. The greater effect that $d$ had on DT could be due to the fact that an increase in $d$ will reduce the rate of penetration of liquid into the interior of the tablets, the specific surface area of the particles, since more particles will come together and bind, and the pore space in which starch particles can swell when wetted by water before disrupting the tablets (20). For $t_{50}, t_{90}$, and $t_{1}$, the effect that $c$ had could be due to the fact that a tablet needs to disintegrate into granules before deaggregating to fine particles. The deaggregation process involves removal of the binder layer around the particles and this depends on the amount of binder coating the particles. The higher the binder concentration, the slower the removal since higher concentration would lead to more binding.

For pregelatinized/pregelatinized starch combinations, the most common ranking of the individual effects of variables on $D T$ was $c>d>\mathrm{N}$, on $t_{50} c>d>\mathrm{N}$, on $t_{90} d>c>\mathrm{N}$ and on $t_{1} c>d>\mathrm{N}$. The greater effect that $c$ had on $D T$, unlike in the case of native/native starch combinations where $d$ had a greater effect, could be due to the fact that pre- 
G. Alebiowu and O. Adelanwa Itiola: Influence of process variables on release properties of paracetamol tablets, Acta Pharm. 57 (2007) 73-86.

Table I. Values of disintegration and dissolution times (min) for paracetamol tablets through the factorial experimental design

\begin{tabular}{|c|c|c|c|c|}
\hline Variables and combinations codes & $D T$ & $t_{50}$ & $t_{90}$ & $t_{1}$ \\
\hline \multicolumn{5}{|l|}{ Native sorghum and plantain starches } \\
\hline $\mathrm{N}_{\mathrm{L}} c_{\mathrm{L}} d_{\mathrm{L}}$ & 0.99 & 12.98 & 21.32 & 14.48 \\
\hline $\mathrm{N}_{\mathrm{L}} c_{\mathrm{H}} d_{\mathrm{L}}$ & 1.50 & 17.42 & 32.88 & 16.27 \\
\hline $\mathrm{N}_{\mathrm{L}} c_{\mathrm{H}} d_{\mathrm{H}}$ & 2.46 & 22.99 & 38.33 & 22.45 \\
\hline $\mathrm{N}_{\mathrm{L}} c_{\mathrm{L}} d_{\mathrm{H}}$ & 1.83 & 16.85 & 27.63 & 18.50 \\
\hline $\mathrm{N}_{\mathrm{H}} c_{\mathrm{H}} d_{\mathrm{L}}$ & 2.45 & 16.37 & 29.28 & 22.83 \\
\hline $\mathrm{N}_{\mathrm{H}} c_{\mathrm{H}} d_{\mathrm{H}}$ & 3.33 & 23.21 & 45.25 & 27.37 \\
\hline $\mathrm{N}_{\mathrm{H}} c_{\mathrm{L}} d_{\mathrm{H}}$ & 2.58 & 18.08 & 34.76 & 14.03 \\
\hline $\mathrm{N}_{\mathrm{H}} c_{\mathrm{L}} d_{\mathrm{L}}$ & 1.75 & 15.07 & 29.48 & 16.76 \\
\hline \multicolumn{5}{|l|}{ Native sorghum and corn starches } \\
\hline $\mathrm{N}_{\mathrm{L}} c_{\mathrm{L}} d_{\mathrm{L}}$ & 0.99 & 12.98 & 21.32 & 14.48 \\
\hline $\mathrm{N}_{\mathrm{L}} c_{\mathrm{H}} d_{\mathrm{L}}$ & 1.50 & 17.42 & 32.88 & 16.27 \\
\hline $\mathrm{N}_{\mathrm{L}} c_{\mathrm{H}} d_{\mathrm{H}}$ & 2.46 & 22.99 & 38.33 & 22.45 \\
\hline $\mathrm{N}_{\mathrm{L}} c_{\mathrm{L}} d_{\mathrm{H}}$ & 1.83 & 16.85 & 27.63 & 18.50 \\
\hline $\mathrm{N}_{\mathrm{H}} c_{\mathrm{H}} d_{\mathrm{L}}$ & 2.29 & 22.84 & 47.48 & 25.23 \\
\hline $\mathrm{N}_{\mathrm{H}} c_{\mathrm{H}} d_{\mathrm{H}}$ & 3.13 & 28.65 & 54.13 & 28.20 \\
\hline $\mathrm{N}_{\mathrm{H}} c_{\mathrm{L}} d_{\mathrm{H}}$ & 2.02 & 20.79 & 43.60 & 16.89 \\
\hline $\mathrm{N}_{\mathrm{H}} c_{\mathrm{L}} d_{\mathrm{L}}$ & 1.69 & 16.74 & 37.35 & 13.30 \\
\hline \multicolumn{5}{|l|}{ Native plantain and corn starches } \\
\hline $\mathrm{N}_{\mathrm{L}} c_{\mathrm{L}} d_{\mathrm{L}}$ & 1.75 & 15.07 & 29.48 & 14.03 \\
\hline $\mathrm{N}_{\mathrm{L}} c_{\mathrm{H}} d_{\mathrm{L}}$ & 2.45 & 16.37 & 29.28 & 22.83 \\
\hline $\mathrm{N}_{\mathrm{L}} c_{\mathrm{H}} d_{\mathrm{H}}$ & 3.33 & 23.21 & 45.25 & 27.37 \\
\hline $\mathrm{N}_{\mathrm{L}} c_{\mathrm{L}} d_{\mathrm{H}}$ & 2.58 & 18.08 & 34.76 & 16.76 \\
\hline $\mathrm{N}_{\mathrm{H}} c_{\mathrm{H}} d_{\mathrm{L}}$ & 2.229 & 22.84 & 47.48 & 25.23 \\
\hline $\mathrm{N}_{\mathrm{H}} c_{\mathrm{H}} d_{\mathrm{H}}$ & 3.13 & 28.65 & 54.13 & 28.20 \\
\hline $\mathrm{N}_{\mathrm{H}} c_{\mathrm{L}} d_{\mathrm{H}}$ & 2.02 & 20.79 & 43.60 & 16.89 \\
\hline $\mathrm{N}_{\mathrm{H}} c_{\mathrm{L}} d_{\mathrm{L}}$ & 1.69 & 16.74 & 37.35 & 13.30 \\
\hline \multicolumn{5}{|c|}{ Pregelatinized sorghum and plantain starches } \\
\hline $\mathrm{N}_{\mathrm{L}} c_{\mathrm{L}} d_{\mathrm{L}}$ & 0.84 & 9.46 & 18.21 & 8.36 \\
\hline $\mathrm{N}_{\mathrm{L}} c_{\mathrm{H}} d_{\mathrm{L}}$ & 1.57 & 13.77 & 22.58 & 13.33 \\
\hline $\mathrm{N}_{\mathrm{L}} c_{\mathrm{H}} d_{\mathrm{H}}$ & 2.20 & 17.22 & 28.27 & 15.62 \\
\hline $\mathrm{N}_{\mathrm{L}} c_{\mathrm{L}} d_{\mathrm{H}}$ & 1.71 & 12.89 & 24.82 & 12.02 \\
\hline $\mathrm{N}_{\mathrm{H}} c_{\mathrm{H}} d_{\mathrm{L}}$ & 1.98 & 12.88 & 28.53 & 14.84 \\
\hline $\mathrm{N}_{\mathrm{H}} c_{\mathrm{H}} d_{\mathrm{H}}$ & 2.60 & 17.43 & 34.41 & 18.09 \\
\hline $\mathrm{N}_{\mathrm{H}} c_{\mathrm{L}} d_{\mathrm{H}}$ & 2.05 & 14.99 & 27.57 & 14.18 \\
\hline $\mathrm{N}_{\mathrm{H}} c_{\mathrm{L}} d_{\mathrm{L}}$ & 1.14 & 12.21 & 24.40 & 11.76 \\
\hline
\end{tabular}


G. Alebiowu and O. Adelanwa Itiola: Influence of process variables on release properties of paracetamol tablets, Acta Pharm. 57 (2007) 73-86.

Table I. (continued)

\begin{tabular}{lllll}
\hline Variables and combinations codes & $D T$ & $t_{50}$ & $t_{90}$ & $t_{1}$ \\
\hline
\end{tabular}

Pregelatinized plantain and corn starches

$\mathrm{N}_{\mathrm{L}} c_{\mathrm{L}} d_{\mathrm{L}}$

1.14

12.21

24.40

11.76

$\mathrm{N}_{\mathrm{L}} c_{\mathrm{H}} d_{\mathrm{L}}$

1.98

12.88

28.53

14.84

$\mathrm{N}_{\mathrm{L}} c_{\mathrm{H}} d_{\mathrm{H}}$

2.60

17.43

34.41

18.09

$\mathrm{N}_{\mathrm{L}} c_{\mathrm{L}} d_{\mathrm{H}}$

2.05

14.99

27.57

14.18

$\mathrm{N}_{\mathrm{H}} c_{\mathrm{H}} d_{\mathrm{L}}$

1.94

17.34

36.69

14.03

$\mathrm{N}_{\mathrm{H}} c_{\mathrm{H}} d_{\mathrm{H}}$

2.47

21.73

43.80

18.60

$\mathrm{N}_{\mathrm{H}} c_{\mathrm{L}} d_{\mathrm{H}}$

1.60

13.16

12.35

$\mathrm{N}_{\mathrm{H}} c_{\mathrm{L}} d_{\mathrm{L}}$

0.97

11.19

8.58

Pregelatinized sorghum and corn starches

$\mathrm{N}_{\mathrm{L}} c_{\mathrm{L}} d_{\mathrm{L}}$

0.84

9.46

18.21

8.36

$\mathrm{N}_{\mathrm{L}} c_{\mathrm{H}} d_{\mathrm{L}}$

1.57

13.77

22.58

13.33

$\mathrm{N}_{\mathrm{L}} c_{\mathrm{H}} d_{\mathrm{H}}$

2.20

17.22

28.27

15.62

$\mathrm{N}_{\mathrm{L}} c_{\mathrm{L}} d_{\mathrm{H}}$

1.71

12.89

24.82

12.02

$\mathrm{N}_{\mathrm{H}} c_{\mathrm{H}} d_{\mathrm{L}}$

1.94

17.34

36.69

14.03

$\mathrm{N}_{\mathrm{H}} c_{\mathrm{H}} d_{\mathrm{H}}$

2.47

21.73

43.80

18.60

$\mathrm{N}_{\mathrm{H}} c_{\mathrm{L}} d_{\mathrm{H}}$

13.16

27.31

12.35

$\mathrm{N}_{\mathrm{H}} c_{\mathrm{L}} d_{\mathrm{L}}$

0.97

11.19

19.69

8.58

Native and pregelatinized sorghum starches

$\mathrm{N}_{\mathrm{L}} c_{\mathrm{L}} d_{\mathrm{L}}$

0.84

9.46

18.21

8.36

$\mathrm{N}_{\mathrm{L}} c_{\mathrm{H}} d_{\mathrm{L}}$

1.57

13.77

22.58

13.33

$\mathrm{N}_{\mathrm{L}} c_{\mathrm{H}} d_{\mathrm{H}}$

2.20

17.22

28.27

15.62

$\mathrm{N}_{\mathrm{L}} c_{\mathrm{L}} d_{\mathrm{H}}$

1.71

12.89

24.82

12.02

1.50

17.42

32.88

16.27

$\mathrm{N}_{\mathrm{H}} c_{\mathrm{H}} d_{\mathrm{H}}$

2.46

22.99

38.33

22.45

$\mathrm{N}_{\mathrm{H}} c_{\mathrm{L}} d_{\mathrm{H}}$

1.83

16.85

27.63

18.50

$\mathrm{N}_{\mathrm{H}} c_{\mathrm{L}} d_{\mathrm{L}}$

0.99

12.98

21.32

14.48

Native and pregelatinized plantain starches

$\mathrm{N}_{\mathrm{L}} c_{\mathrm{L}} d_{\mathrm{L}}$

1.14

12.21

24.40

11.76

$\mathrm{N}_{\mathrm{L}} c_{\mathrm{H}} d_{\mathrm{L}}$

1.98

12.88

28.53

14.84

$\mathrm{N}_{\mathrm{L}} c_{\mathrm{H}} d_{\mathrm{H}}$

2.60

17.43

34.41

18.09

$\mathrm{N}_{\mathrm{L}} c_{\mathrm{L}} d_{\mathrm{H}}$

2.05

14.99

27.57

14.18

$\mathrm{N}_{\mathrm{H}} c_{\mathrm{H}} d_{\mathrm{L}}$

2.45

16.37

29.28

22.83

$\mathrm{N}_{\mathrm{H}} c_{\mathrm{H}} d_{\mathrm{H}}$

3.33

23.21

45.25

27.37

$\mathrm{N}_{\mathrm{H}} c_{\mathrm{L}} d_{\mathrm{H}}$

2.58

18.08

34.76

16.76

$\mathrm{N}_{\mathrm{H}} c_{\mathrm{L}} d_{\mathrm{L}}$

1.75

15.07

29.48

14.03 
G. Alebiowu and O. Adelanwa Itiola: Influence of process variables on release properties of paracetamol tablets, Acta Pharm. 57 (2007) 73-86.

Table I. (continued)

\begin{tabular}{lcccc}
\hline Variables and combinations codes & $D T$ & $t_{50}$ & $t_{90}$ & $t_{1}$ \\
\hline Native and pregelatinized corn starches & & & & \\
$\mathrm{N}_{\mathrm{L}} c_{\mathrm{L}} d_{\mathrm{L}}$ & 0.97 & 11.19 & 19.69 & 8.58 \\
$\mathrm{~N}_{\mathrm{L}} c_{\mathrm{H}} d_{\mathrm{L}}$ & 1.94 & 17.34 & 36.69 & 14.03 \\
$\mathrm{~N}_{\mathrm{L}} c_{\mathrm{H}} d_{\mathrm{H}}$ & 2.47 & 21.73 & 43.80 & 18.60 \\
$\mathrm{~N}_{\mathrm{L}} c_{\mathrm{L}} d_{\mathrm{H}}$ & 1.60 & 13.16 & 27.31 & 12.35 \\
$\mathrm{~N}_{\mathrm{H}} c_{\mathrm{H}} d_{\mathrm{L}}$ & 2.29 & 22.84 & 47.48 & 25.23 \\
$\mathrm{~N}_{\mathrm{H}} c_{\mathrm{H}} d_{\mathrm{H}}$ & 3.13 & 28.65 & 54.13 & 28.20 \\
$\mathrm{~N}_{\mathrm{H}} c_{\mathrm{L}} d_{\mathrm{H}}$ & 2.02 & 20.79 & 43.60 & 16.89 \\
$\mathrm{~N}_{\mathrm{H}} c_{\mathrm{L}} d_{\mathrm{L}}$ & 1.69 & 16.74 & 37.35 & 13.30 \\
\hline
\end{tabular}

gelatinized starch binders, are cold water swellable (7). This swellability would undermine the effects of $d$ on the tablets. Concentration had a greater effect because a higher concentration of binder will lead to the formation of additional bonds due to the increase in the area of contact between particles when binders are forced into interparticular spaces. For $t_{50}$ and $t_{1}$, the effect of $c$ could be due to the reason given above for native/native starch combinations.

For native/pregelatinized starch combinations, the most common ranking of the individual effects of the variables on $D T, t_{50}$ and $t_{1}$ was $c>d>\mathrm{N}$ while no specific ranking was observed for $t_{90}$. The ranking obtained for $D T$ and the greater effect that $c$ had could be due to the reason given above for native/native starch combinations. The higher effect of $\mathrm{N}$ over $d$ was expected since pregelatinized starches are cold water-swellable and have a higher swelling capacity $(10,19)$, which would assist in decreasing the dissolution times whereas for native starches, a lower swelling capacity was observed which would make the dissolution time higher, as seen in Table IV. The swellability of pregelatinized starches would undermine the effect that $d$ would have on the penetration rate of water into the tablets.

From Table II, it can be seen that nearly all the individual effects were positive apart from a few cases of $\mathrm{N}$ for plantain/corn starches, which were negative. The positiveness of the individual effects indicates that increasing the variables $(c, d, N)$ from a low level to a high level would lead to an increase in the disintegration and dissolution times. The magnitude of the individual effects observed on the different native starch combinations, pregelatinized starch combinations and native/pregelatinized starch combinations point to the fact that the formulator needs to carefully choose the binders that will enable the production of tablets with good disintegration and dissolution properties. The individual effects obtained for native/pregelatinized and pregelatinized/pregelatinized starch combinations showed a general ranking of $c>d>\mathrm{N}$, while for native/native starch combinations, a common ranking of $d>c>\mathrm{N}$ was obtained along with $c>d>\mathrm{N}$. This observation could be due to the effect that pregelatinization would have on the swelling of the starches, which would probably undermine the effect of $d$ on the tablets. This suggests that the form of a starch binder would have considerable influence on the effect that the relative density of a tablet has on the disintegration/dissolution parameters. 
G. Alebiowu and O. Adelanwa Itiola: Influence of process variables on release properties of paracetamol tablets, Acta Pharm. 57 (2007) 73-86.

Table II. Quantitative effect of relative tablet density (d), binder concentration (c) and the nature of binder $(N)$ on the disintegration time and dissolution parameters of paracetamol tablets

\begin{tabular}{ccccc}
\hline \multirow{2}{*}{ Variable } & \multicolumn{4}{c}{ Independent coefficient } \\
\cline { 2 - 5 } & $D T$ & $t_{50}$ & $t_{90}$ & $t_{1}$ \\
\hline
\end{tabular}

Native sorghum and plantain starches

$\begin{array}{lllll}\mathrm{N} & 0.83 & 0.60 & 4.55 & 2.34 \\ c & 0.65 & 4.25 & 8.14 & 6.29 \\ d & 0.88 & 4.82 & 8.24 & 3.00\end{array}$

Native sorghum and corn starches

$\begin{array}{lrrrr}\mathrm{N} & 0.59 & 4.69 & 18.10 & 2.98 \\ c & 0.71 & 6.13 & 10.73 & 7.24 \\ d & 0.74 & 6.82 & 6.16 & 4.19\end{array}$

Native plantain and corn starches

$\begin{array}{lrrrr}\mathrm{N} & -0.24 & 4.07 & 10.95 & 0.66 \\ c & 0.79 & 5.10 & 10.73 & 10.66 \\ d & 0.72 & 4.93 & 8.54 & 3.46\end{array}$

Pregelatinized sorghum and plantain starches

$\begin{array}{llrrr}\mathrm{N} & 0.36 & 1.04 & 5.26 & 2.38 \\ c & 0.65 & 23.94 & 4.70 & 3.89 \\ d & 0.76 & 3.55 & 5.34 & 2.90\end{array}$

Pregelatinized plantain and corn starches

$\begin{array}{lrrrr}\mathrm{N} & 0.20 & 1.48 & 4.22 & -3.83 \\ c & 0.81 & 4.46 & 11.11 & 4.67 \\ d & 0.67 & 3.42 & 5.94 & 3.50\end{array}$

Pregelatinized sorghum and corn starches

\begin{tabular}{|c|c|c|c|c|}
\hline $\mathrm{N}$ & 0.16 & 2.52 & 8.40 & 1.06 \\
\hline$c$ & 0.76 & 5.84 & 10.33 & 5.07 \\
\hline$d$ & 0.66 & 3.31 & 11.68 & 3.57 \\
\hline \multicolumn{5}{|c|}{ Native and pregelatinized sorghum starches } \\
\hline $\mathrm{N}$ & 0.11 & 4.22 & 6.57 & 5.59 \\
\hline$c$ & 0.59 & 4.80 & 7.52 & 3.58 \\
\hline$d$ & 0.82 & 4.08 & 6.01 & 4.04 \\
\hline \multicolumn{5}{|c|}{ Native and pregelatinized plantain starches } \\
\hline $\mathrm{N}$ & 0.58 & 3.80 & 5.96 & 5.53 \\
\hline$c$ & 0.71 & 2.38 & 5.31 & 6.60 \\
\hline$d$ & 0.81 & 4.29 & 7.57 & 3.23 \\
\hline \multicolumn{5}{|c|}{ Native and pregelatinized corn starches } \\
\hline $\mathrm{N}$ & 0.54 & 6.40 & 13.77 & 7.51 \\
\hline$c$ & 0.89 & 7.17 & 13.54 & 8.70 \\
\hline$d$ & 0.58 & 4.05 & 6.91 & 3.72 \\
\hline
\end{tabular}


G. Alebiowu and O. Adelanwa Itiola: Influence of process variables on release properties of paracetamol tablets, Acta Pharm. 57 (2007) 73-86.

Table III. Quantitative effects of relative tablet density (d), binder concentration (c) and the nature of binder $(N)$ on the disintegration and dissolution times of paracetamol tablets

\begin{tabular}{lllll}
\hline \multirow{2}{*}{ Variable } & \multicolumn{5}{l}{ Interaction coefficient } \\
\cline { 2 - 5 } & $D T$ & $t_{50}$ & $t_{90}$ & $t_{1}$ \\
\hline
\end{tabular}

Native sorghum and plantain starches

$\begin{array}{lrrrr}\mathrm{N}-c & 0.08 & -1.04 & -2.99 & -3.42 \\ \mathrm{~N}-d & -0.02 & 0.10 & 2.37 & -2.10 \\ c-d & 0.04 & 1.38 & 2.46 & 2.36\end{array}$

Native sorghum and corn starches

$\begin{array}{rrrrr}\mathrm{N}-c & 0.14 & 0.84 & -0.40 & 4.37 \\ \mathrm{~N}-d & -0.16 & 0.10 & 0.28 & -0.78 \\ c-d & 0.16 & 0.86 & -0.11 & 0.38\end{array}$

Native plantain and corn starches

$\begin{array}{lrlrr}\mathrm{N}-c & -0.37 & 1.88 & 2.59 & 0.96 \\ \mathrm{~N}-d & -0.13 & 0.003 & -2.07 & -0.18 \\ c-d & 0.14 & 1.40 & 2.77 & 0.28\end{array}$

Pregelatinized sorghum and plantain starches

$\begin{array}{lrrrr}\mathrm{N}-c & 0.04 & -1.38 & 0.79 & -0.39 \\ \mathrm{~N}-\boldsymbol{d} & 0.01 & 0.11 & -0.81 & 0.07 \\ c-d & -0.13 & 0.48 & 0.48 & -0.13\end{array}$

Pregelatinized plantain and corn starches

$\begin{array}{lrrrr}\mathrm{N}-c & 0.11 & 2.90 & 5.63 & 1.78 \\ \mathrm{~N}-\boldsymbol{d} & -0.09 & -0.24 & 1.42 & 0.67 \\ c-d & -0.10 & 1.05 & 0.55 & 0.41\end{array}$

Pregelatinized sorghum and corn starches

$\begin{array}{lrrrr}\mathrm{N}-c & 0.15 & 1.52 & 6.41 & 0.78 \\ \mathrm{~N}-d & -0.08 & -0.14 & 0.61 & -1.49 \\ c-d & -0.08 & 0.61 & -0.36 & -0.14\end{array}$

Native and pregelatinized sorghum starches

$\begin{array}{lrrrr}\mathrm{N}-c & -0.02 & 2.98 & 3.61 & -0.71 \\ \mathrm{~N}-d & 0.07 & 0.64 & -0.13 & 1.06 \\ c-d & -0.03 & -0.35 & 2.05 & 0.20\end{array}$

Native and pregelatinized plantain starches

$\begin{array}{lllrl}\mathrm{N}-c & 0.01 & 0.83 & -0.17 & 3.10 \\ \mathrm{~N}-\boldsymbol{d} & 0.04 & 0.63 & 3.05 & 0.40 \\ c-d & 0.06 & 1.40 & 3.35 & 1.34\end{array}$

Native and pregelatinized corn starches

$\begin{array}{llllr}\mathrm{N}-c & -0.03 & 1.72 & -3.21 & 2.88 \\ \mathrm{~N}-d & 0.003 & 0.87 & -0.37 & -0.44 \\ c-d & 0.10 & 1.04 & -0.03 & 0.04\end{array}$


G. Alebiowu and O. Adelanwa Itiola: Influence of process variables on release properties of paracetamol tablets, Acta Pharm. 57 (2007) 73-86

Table IV. Rankings obtained for the independent coefficient effects on the disintegration and dissolution times of paracetamol tablets

\begin{tabular}{lcccc}
\hline \multicolumn{1}{c}{ Formulation } & \multicolumn{4}{c}{ Independent rankings } \\
\cline { 2 - 4 } & \multicolumn{1}{c}{$t_{50}$} & $t_{1}$ & $t_{90}$ \\
\hline Native/native starches & & & \\
Sorghum/plantain & $d>\mathrm{N}>c$ & $d>c>\mathrm{N}$ & $c>>d>\mathrm{N}$ & $d>c>\mathrm{N}$ \\
Sorghum/corn & $d>c>\mathrm{N}$ & $d>c>\mathrm{N}$ & $c>d>\mathrm{N}$ & $\mathrm{N}>c>d$ \\
Plantain/corn & $c>d>>\mathrm{N}$ & $c>d>\mathrm{N}$ & $c>>d>>\mathrm{N}$ & $\mathrm{N}>c>d$ \\
Pregelatinized/pregelatinized starches & & & \\
Sorghum/plantain & $d>>c>\mathrm{N}$ & $c>>d>\mathrm{N}$ & $c>d>\mathrm{N}$ & $d>\mathrm{N}>c$ \\
Sorghum/corn & $c>d>\mathrm{N}$ & $c>d>\mathrm{N}$ & $c>d>\mathrm{N}$ & $d>c>\mathrm{N}$ \\
Plantain/corn & $c>d>\mathrm{N}$ & $c>d>\mathrm{N}$ & $c>\mathrm{N}>d$ & $c>d>\mathrm{N}$ \\
Native/pregelatinized starches & & & \\
Sorghum/plantain & $d>>c>\mathrm{N}$ & $c>>d>\mathrm{N}$ & $c>d>\mathrm{N}$ & $d>\mathrm{N}>c$ \\
Sorghum/corn & $c>d>\mathrm{N}$ & $c>d>\mathrm{N}$ & $c>d>\mathrm{N}$ & $d>c>\mathrm{N}$ \\
Plantain/corn & $c>d>\mathrm{N}$ & $c>d>\mathrm{N}$ & $c>\mathrm{N}>d$ & $c>d>\mathrm{N}$ \\
\hline
\end{tabular}

Table $V$. Rankings obtained for the interaction variables on the disintegration and dissolution times of paracetamol tablets

\begin{tabular}{lcccc}
\hline \multirow{2}{*}{ Formulations } & \multicolumn{4}{c}{ Interaction effects } \\
\cline { 2 - 5 } & \multicolumn{1}{c}{$t_{50}$} & $t_{1}$ & $t_{90}$ \\
\hline Native/native starches & & & \\
Sorghum/plantain & $\mathrm{N}-c>c-d>\mathrm{N}-d$ & $c-d>\mathrm{N}-c>\mathrm{N}-d$ & $\mathrm{~N}-c>c-d>\mathrm{N}-d$ & $\mathrm{~N}-c>c-d>\mathrm{N}-d$ \\
Sorghum/corn & $c-d=\mathrm{N}-d>\mathrm{N}-c$ & $c-d>\mathrm{N}-c>\mathrm{N}-d$ & $\mathrm{~N}-c>\mathrm{N}-d>c-d$ & $\mathrm{~N}-c>\mathrm{N}-d>c-d$ \\
Plantain/corn & $\mathrm{N}-c>c-\mathrm{N}>\mathrm{N}-d$ & $\mathrm{~N}-c>c-\mathrm{N}>\mathrm{N}-d$ & $\mathrm{~N}-c>c-\mathrm{N}>\mathrm{N}-d$ & $c-d>\mathrm{N}-c>\mathrm{N}-d$ \\
Pregelatinized/pregelatinized starches & & & \\
Sorghum/plantain & $c-d>\mathrm{N}-c>\mathrm{N}-d$ & $\mathrm{~N}-c>c-d>\mathrm{N}-d$ & $\mathrm{~N}-c>c-d>\mathrm{N}-d$ & $\mathrm{~N}-d>\mathrm{N}-c>c-d$ \\
Sorghum/corn & $\mathrm{N}-c>c-d=\mathrm{N}-d$ & $\mathrm{~N}-c>c-d>\mathrm{N}-d$ & $\mathrm{~N}-d>\mathrm{N}-c>c-d$ & $\mathrm{~N}-c>c-d>\mathrm{N}-d$ \\
Plantain/corn & $\mathrm{N}-c>c-d>\mathrm{N}-d$ & $\mathrm{~N}-c>c-d>\mathrm{N}-d$ & $\mathrm{~N}-c>\mathrm{N}-d>c-d$ & $\mathrm{~N}-c>\mathrm{N}-d>c-d$ \\
Native/pregelatinized starches & & & \\
Sorghum/plantain & $\mathrm{N}-d>c-d>d-\mathrm{N}$ & $\mathrm{N}-c>>\mathrm{N}-d>c-d$ & $\mathrm{~N}-d>\mathrm{N}-c>c-d$ & $\mathrm{~N}-c>c-d>>\mathrm{N}-d$ \\
Sorghum/corn & $c-d>\mathrm{N}-d>\mathrm{N}-c$ & $c-d>\mathrm{N}-c>\mathrm{N}-d$ & $\mathrm{~N}-c>c-d>\mathrm{N}-d$ & $c-d>\mathrm{N}-d>\mathrm{N}-c$ \\
Plantain/corn & $c-d>>\mathrm{N}-c>\mathrm{N}-d$ & $\mathrm{~N}-c>c-d>\mathrm{N}-d$ & $\mathrm{~N}-c>>\mathrm{N}-d>c-d$ & $\mathrm{~N}-c>\mathrm{N}-d>c-d$ \\
\hline
\end{tabular}


G. Alebiowu and O. Adelanwa Itiola: Influence of process variables on release properties of paracetamol tablets, Acta Pharm. 57 (2007) 73-86.

\section{Interaction effects}

The interaction coefficients (Table III) indicate the effects of the variables in combination. The rankings of interaction effects are shown in Table V. The results show that for all the parameters for native/native, pregelatinized/pregelatinized and native/pregelatinized starch binder combinations, the interactions between $\mathrm{N}$ and $c$ were generally the highest and those between $\mathrm{N}$ and $d$ generally the lowest. This suggests that a change in the binding agent would have considerable influence on the effects the binder concentration will have on the tablet parameters studied. Thus, the type of starch used as binder is important in formulation studies.

The interaction coefficients (Tables III and V) also show that there were considerable interactions between the concentration of binder, $c$, and the other two variables $\mathrm{N}$ and $d$. This may be due to the fact that the starch binders are plasto-elastic in nature and undergo extensive plastic deformation under high compressional forces to form strong solid bonds between particles, the number of bonds formed depending considerably on the concentration of the binder employed. Concerning tablet properties, the effects of $c$ have been shown (3) to be strongly related to the relative density of the tablet, $d$, and the nature of the binding agent, $\mathrm{N}$, employed in the formulation.

\section{CONCLUSIONS}

The results of the present work show that pregelatinization influences the interaction between variables and that the form of starch binder will have considerable influence on the release properties of a tablet. The study also revealed that though the nature of a starch binder will have influence on the release properties of a tablet, the concentration is the most important independent variable, and will have more influence on the effect of other variables affecting release properties of a tablet. Furthermore, the work suggests that the tested sorghum and plantain starches exhibit comparable quantitative effects on the release properties of paracetamol tablets to those of corn starch BP. This type of study will be useful in the optimization of materials investigating especially during the development of dosage forms. It will also be relevant when researching the influence of different parameters on dosage forms.

\section{REFERENCES}

1. R. C. Woolfall, An approach to product formulation, Soap Perfum. Cosmet. 37 (1964) 965-970.

2. S. Zubair, N. Esezobo and N. Pilpel, The effects of interacting variables on the tensile strength, disintegration and dissolution of paracetamol tablets, J. Pharm. Pharmacol. 40 (1988) 278-281.

3. O. A. Itiola and N. Pilpel, Effects of interacting variables on the disintegration and dissolution of metronidazole tablets, Pharmazie 51 (1996) 987-989.

4. G. Alebiowu and O. A. Itiola, Effects of pregelatinization of starch binders on the interacting variables acting on the mechanical properties of a paracetanol tablet formulation, STP Pharma Sci. 12 (2002) 379-383. 
G. Alebiowu and O. Adelanwa Itiola: Influence of process variables on release properties of paracetamol tablets, Acta Pharm. 57 (2007) 73-86.

5. G. Alebiowu and O. A. Itiola, The influence of pregelatinized starch disintegrants on interacting variables that act on disintegrant properties, Pharm. Technol. 27 (2003) 28-34.

6. M. K. Kottke, H. R. Chueh and C. T. Rhodes, Comparison of disintegrant and binder activity of three corn starch products, Drug Dev. Ind. Pharm. 18 (1992) 2207-2223.

7. N. Visavarungroj and J. P. Remon, An evaluation of hydroxypropyl starch as disintegrant and binder in tablet formulation, Drug Dev. Ind. Pharm. 17 (1991) 1389-1396.

8. S. Esezobo and V. Ambujam, An evaluation of starch of starch obtained from plantain, Musa paradisiaca, as a binder and disintegrant for compressed tablets, J. Pharm. Pharmacol. 34 (1982) 761-765.

9. J. S. M. Garr and A. B. Bangudu, Evaluation of sorghum starch as a tablet excipient, Drug Dev. Ind. Pharm. 17 (1991) 1-6.

10. G. Alebiowu and O. A. Itiola, Compressional characteristics of native and pregelatinized forms of sorghum, plain and corn starches and the mechanical properties of their tablets, Drug Dev. Ind. Pharm. 28 (2002) 663-672.

11. G. Alebiowu and O. A. Itiola, The effects of starches on the mechanical properties of paracetamol tablet formulations. I. Pregelatinization of starch binders, Acta Pharm. 53 (2003) 231-237.

12. G. Alebiowu and O. A. Itiola, Effects of starches on the mechanical properties of paracetamol tablet formulations. II. Sorghum and plantain starches as disintegrants, Acta Pharm. 53 (2003) 313-320.

13. S. Kitazawa, I. Johno, T. Minouchi and J. Okada, Interpretation of dissolution rate data from in-vitro testing of compressed tablets, J. Pharm. Pharmacol. 29 (1977) 453-459

14. British Pharmacopoeia, Her Majesty's Stationery Office, London 2005.

15. A. H. Young, Fractionation of Starch, in Starch Chemistry and Technology, $2^{\text {nd }}$ ed. (Eds. R. L. Whistler, J. N. BeMiller and E. F Paschall), Academic Press, London 1984, pp. 249-283.

16. The Pharmaceutical Codex, $11^{\text {th }}$ ed., The Pharmaceutical Press, London 1979, p. 510.

17. J. Herman, J. P. Remon and J. De Vilder, Modified starches as hydrophilic matrices for controlled oral delivery. I. Production and characterization of thermally modified starches, Int. J. Pharm. 56 (1989) 51-63.

18. USP 24/NF 18, USP Convention, Rockville 1999, pp. 1942-1943.

19. L. Sanchez, S. Torrrado and J. L. Lastres, Gelatinized/freeze-dried starch as excipient in sustained release tablets, Int. J. Pharm 115 (1995) 201-208.

20. N. Pilpel, S. O. Otuyemi and T. R. R. Kurup, Factors affecting the disintegration and dissolution of chloroquine phosphate/starch tablets, J. Pharm. Pharmacol. 30 (1978) 214-219.

$S A \check{Z} E T A K$

\section{Utjecaj varijabli na oslobađanje paracetamola iz tableta}

GBENGA ALEBIOWU i OLUDELE ADELANWA ITIOLA

$2^{3}$ faktorijalni eksperimentalni dizajn upotrebljen je za kvantitativno ispitivanje pojedinačnih učinaka i međudjelovanja vrste veziva $(\mathrm{N})$, njegove koncentracije $(c)$ i relativne gustoće tableta $(d)$ na vrijeme raspadanja $\left(t_{\mathrm{d}}\right)$ i oslobađanja, $t_{1}, t_{50}$ i $t_{90}$, paracetamola iz tableta. Faktorijalni dizajn je osim toga upotrebljen za proučavanje kvantitativnih učinaka preželatinizacije škrobnog veziva na $N, c$ i $d$. Općenito, učinak na $t_{d}, t_{1}, t_{50}$ i $t_{90} u$ tabletama s nativnim/nativnim, preželatiniziranim/preželatiniziranim i nativnim/pre- 
G. Alebiowu and O. Adelanwa Itiola: Influence of process variables on release properties of paracetamol tablets, Acta Pharm. 57 (2007) 73-86.

želatiniziranim škrobom bio je $c>d>\mathrm{N}$. Međudjelovanja su rangirana kako slijedi: $\mathrm{N}-c$ $>c-d>\mathrm{N}-d$, za sve isptivane uzorke tableta. Rezultati pokazuju da koncentracija veziva (c) ima značajan učinak na $t_{\mathrm{d}}, t_{1}, t_{50}$ i $t_{90}$ tableta.

Ključne riječi: preželatinizacija, škrob, sorgum, plantain, raspadanje, oslobađanje

Department of Pharmaceutics, Faculty of Pharmacy, Obafemi Awolowo University, Ile-Ife, Nigeria

Department of Pharmaceutics and Industrial Pharmacy, Faculty of Pharmacy, University of Ibadan Ibadan, Nigeria 